\title{
Effect of magnetic field on fluid flow characteristics and augmentation of heat transfer in a heat exchanger
}

\author{
Mohammed Almeshaal* and Sujoy Saha** \\ * Department of Mechanical Engineering, College of Engineering, Imam Mohammad Ibn Saud Islamic University (IMSIU), Riyadh, \\ Saudi Arabia \\ ** Department of Marine Engineering (Mechanical), Indian Maritime University (A Central University, Govt. of India), Taratala, Kolkata, \\ West Bengal, India \\ *Corresponding Author: maalmeshaal@imamu.edu.sa
}

$\begin{array}{ll}\text { Submitted } & : 18 / 10 / 2020 \\ \text { Revised } & : 24 / 01 / 2021 \\ \text { Accepted } & : 20 / 03 / 2021\end{array}$

\begin{abstract}
The study of fluid flow, subjected to an external magnetic field, has become an attractive and demanding research area because of its huge applications. In this work, water base magnetic nanofluid dynamics, taking into account the magnetohydrodynamics (MHD) phenomenon, have been explicitly investigated. In this study, governing equations are coupled with magnetohydrodynamics (MHD) and are solved with the help of a finite volume procedure based on a control volume approach. The numerical outcomes of the simulation are depicted and discussed sequentially in terms of different contour and flow parameters. The impact of magnetic number arising from magnetohydrodynamics (MHD) ranging from 302 to 377 for a fixed Reynolds number of 100 on the flow characteristics has been presented in detail. The flow parameters like wall shear and pressure of wall are increased with increasing the magnetic number, and the number of recirculating bubbles increases with decreasing the magnetic number. Thus, to generate the maximum number of recirculating bubbles, a lower magnetic number is being recommended. The formation of the recirculating zone increases the retention time of fluid, which results in the enhancement of heat transfer for a specific surface of a heat exchanger.
\end{abstract}

Keywords: Magnetic number; Laminar; Streamlines contour; Vorticity contour; Wall shear stress; Wall static pressure.

\section{NOMENCLATURE}
$p_{\text {stu }} \quad$ Upper wall static pressure, $\mathrm{N} / \mathrm{m}^{2}$
$p_{s t b} \quad$ Bottom wall static pressure, $\mathrm{N} / \mathrm{m}^{2}$
Re Reynolds Number 


$\begin{array}{ll}\mathrm{M}_{\mathrm{nM}} & \text { Magnetic number arising from MHD } \\ \mathrm{u} & \text { Velocity in x-direction, } \mathrm{ms}^{-1} \\ \mathrm{v} & \text { Velocity in y-direction, } \mathrm{ms}^{-1} \\ \psi & \text { Stream function } \\ \psi_{\text {max }} & \text { Maximum magnitude of stream function } \\ \mathrm{H} & \text { Magnetic field intensity, }\left[\mathrm{Amp} \cdot \mathrm{m}^{-1}\right] \\ \rho & \text { Density of fluid, kg } \mathrm{m}^{3} \\ \mu_{o} & \text { Magnetic permittivity, } \mathrm{Web} \cdot \mathrm{m}^{-1} \mathrm{Amp} \mathrm{m}^{-1} \\ \mu & \text { Viscosity, Ns/m } \mathrm{m}^{2} \\ \sigma & \text { Electrical conductivity, } \\ \mathrm{B} & \text { Magnetic induction } \\ \tau_{u} & \text { Upper wall shear stress, } \mathrm{N} / \mathrm{m}^{2} \\ \tau_{b} & \text { Bottom wall shear stress, } \mathrm{N} / \mathrm{m}^{2}\end{array}$

\section{INTRODUCTION}

The dynamics of magnetic fluid in the emergence of the magnetic field come up with immense success in terms of its use in industry, such as heat exchanger, combustor, and mixing chamber. The motion of magnetic fluid in a channel is tightly related to the condition of flow and applied magnetic field from outside of the channel. Apart from that, how its stability and its distributive behavior are altered through the imposed magnetic field along with the condition of the flow is extremely important. The mathematical modeling and the numerical simulations show a promising contribution to the further advancements of the above-mentioned applications. To meet the objective, initially, it is necessary to attain the fundamental insights of the fluid dynamics with the consideration of magnetic field effects. Magnetic fluids are a unique class of fluids, which was invented in 1963 by NASA's Steve Papell. A wide range of technological problems can be solved through magnetic fluid flow in the existence of a magnetic field.

It is noted that extensive experimental, numerical, and theoretical research investigations have been performed by researchers in the field of magnetic fluid flow. According to the study of Hayat et al. (2007), the two-dimensional (2D) laminar and turbulent flow of fluid are used with considering both ferrohydrodynamics (FHD) and magnetohydrodynamics (MHD) phenomena. Takeuchi et al. (2008) have introduced an investigation on turbulent flow. Malekzadeshet al. (2011) have experimentally examined an effect of a magnetic field on steady flow with considering MHD phenomenon. Khashan et al. (2011) have considered liquid coursing through a 2D channel subjected to the magnetic field. Hayat et al. (2012) have researched the peristaltic MHD flow of a liquid in a channel. Abd-Alla et al. (2012) have examined the impact of the magnetic field on the peristaltic movement of liquid in an adaptable cylinder. Gedik et al. (2012) have explored Computational Fluid Dynamics (CFDs) within the sight of a 
constant magnetic field. Galindo et al. (2012) have contemplated both numerical and exploratory displaying of a vertical inclination freeze type flow affected by magnetic fields. Srivastava and Deo (2012) have considered the influence of the transverse magnetic field on a liquid. Aminfar et al. (2012) have investigated the flow of ferrofluid in a cylinder with a flexible portion within the sight of the fluctuating magnetic field. Akram et al. (2013) have examined the impact of the actuated magnetic field on the peristaltic transport of a liquid. Bitla and Iyengar (2014) have diagnostically researched incompressible fluid flow affected by a magnetic field. Muthtamilselvan and Doh (2014) have executed a numerical examination on laminar flow within the sight of a magnetic field. Azizian et al. (2014) have tentatively examined the effect of outside magnetic fields on laminar flow. Dritselis and Knaepen (2014) have done their numerical recreation on magnetic fluid flow subjected to a uniform transverse magnetic field. Turk et al. (2014) have investigated numerically the effect of a spatially varying outer magnetic field on 2D fluid flow. Akram and Nadeem (2014) have played out a systematic examination of the peristaltic flow of liquid under a magnetic field. S. Saha and S. Chakrabarti (2016) have numerically examined the impact of Reynolds number on the ferromagnetic liquid with considered MHD phenomenon. Maatki et al. (2016) have presented a numerical work on the impact of the magnetic field on the three-dimensional fluid flow with the help of using the finite volume method. Mebarek-Oudina (2017) has presented a numerical examination on natural convection. C. Maatki et al. (2017) have numerically studied the effect of magnetic field on electromagnetic parameters with considering fine volume method. Afzal et al. (2019) have presented an experimental investigation on helical coil heat exchanger with considering lminar flow. ThankGod Enatimi Boye and Olusegun David Samuel (2020) have presented a computational model on transient flow of fluid through a pipeline. Kolsi et al. (2020) have performed a numerical study on the effect of magnetic fields on natural convection. Zaim et al. (2020) have investigated magnetohydrodynamic (MHD) flow of fluid with considered natural convection. Mebarek-Oudina et al. (2020) have studied the effect of a transverse magnetic field with considering magnetohydrodynamics on a generation of entropy. Mebarek-Oudina et al. (2020) have numerically investigated the influence of external magnetic fields on the flow of water-based nanofluids. Mebarek-Oudina et al. (2020) have presented the effect of magnetic field on electrically conducting fluids considering the principle of magnetohydrodynamics (MHD). Swain et al. (2021) have studied the impact of variable external magnetic fields on water-based hybrid nanofluid. S. Saha and S. Chakrabarti (2020) have examined the 2D turbulent flow subjected to a magnetic field, coursing through a square-shaped channel. Abo-Dahab et al. (2021) have studied the flow of viscoelastic fluid under the influence of the transverse magnetized field.

From the above-mentioned review of the literature, it is noted that although many researchers have investigated experimentally, numerically, and theoretically, the flow of magnetic fluid is through different types of channels such as the rectangular channel and 2D nonuniform channel. But, a systematic detailed investigation on the improvement of heat transfer because of the change of nondimensional Magnetic number with considering MHD phenomenon and its impact on various flow characteristics has not been addressed so far. In the present work, a scrupulous effort has been given to supplement the augmentation of heat transfer rate in a heat exchanger and the various extensive crucial flow characteristics of a magnetic fluid.

\section{MATHEMATICAL MODEL}

\subsection{Governing Equations}

In this numerical examination, magnetic, viscous, and incompressible liquid has been viewed as moving through a rectangular channel subjected to an applied magnetic field with considering magnetohydrodynamics (MHD) phenomenon. A simulated diagram of the computational zone is given in Figure 1. 


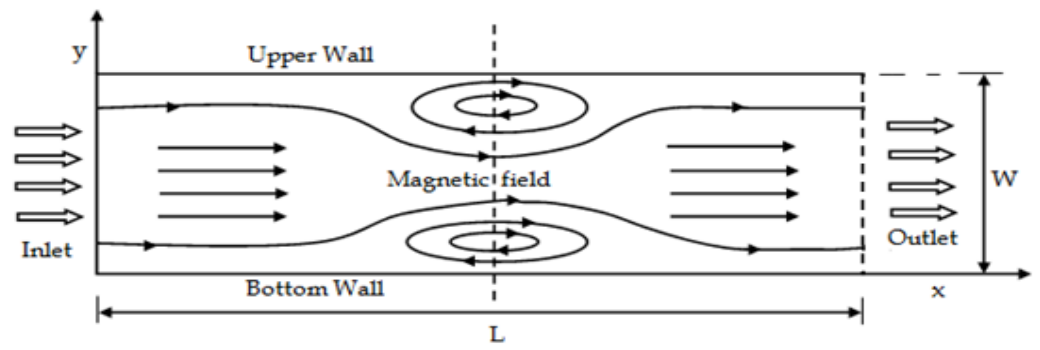

Figure 1. A schematic diagram of the considered model.

The governing equations such as continuity equation and momentum equation along both the coordinate directions, i.e., along $\mathrm{x}$-direction and $\mathrm{y}$-direction, with taking into account the principle of MHD and laminar flow can be are represented as

$\frac{\partial u}{\partial x}+\frac{\partial v}{\partial x},(1)$

$\rho\left(u \frac{\partial u}{\partial x}+v \frac{\partial u}{\partial y}\right)=-\frac{\partial p}{\partial x}+\mu_{0} M \frac{\partial H}{\partial x}-\sigma B^{2} u+\mu\left(\frac{\partial^{2} u}{\partial x^{2}}+\frac{\partial^{2} u}{\partial y^{2}}\right),(2)$

$\rho\left(\mathrm{u} \frac{\partial \mathrm{v}}{\partial \mathrm{x}}+\mathrm{v} \frac{\partial \mathrm{v}}{\partial \mathrm{y}}\right)=-\frac{\partial \mathrm{p}}{\partial \mathrm{y}}+\mu\left(\frac{\partial^{2} \mathrm{v}}{\partial \mathrm{x}^{2}}+\frac{\partial^{2} \mathrm{v}}{\partial \mathrm{y}^{2}}\right),(3)$

$B=\mu_{0} H$

(Khashan SA, et al. 2011)

Where

$\mu_{0}=$ the magnetic permeability of the magnetic medium,

$\rho=$ fluid density,

$\mu=$ viscosity of the flowing fluid,

$H=$ magnetic field strength which is the amount of force imparted on moving magnetic particle ,by the magnetic field,

$\sigma=$ electrical conductivity of the water-based magnetic fluid,

B = magnetic induction (Saha S, Chakrabarti S. 2020).

These equations have likewise also been utilized by Hayat et al. (2007) during their investigation.

\subsection{Boundary Conditions (BCs)}

The following BCs are included in the current work:

i) At the walls: both components of velocities are considered to be zero, i.e.,

$$
u=0, v=0 .
$$

ii) At inlet: the component of velocity along the x-direction is considered to be uniform, and the velocity component along y-direction is considered as zero, i.e., 


$$
u=\frac{R_{e} \mu}{\rho w} \text { and } v=0
$$

iii) At exit: ambient pressure is considered.

The type of flow and impact of the magnetic field on magnetic fluid flow can be determined by the nondimensional parameters, such as Reynolds number and magnetic number. The mathematical expressions of the above-mentioned parameters are as follows:

Reynolds number, $R_{e}=\frac{\rho U W}{\mu}$.

The magnetic number from MHD [18], $M=\frac{\mu_{0}^{2} H^{2} W^{2} \sigma}{\mu}$.

\subsection{Properties of Magnetic Fluid}

In Table 1, "the different physical properties of magnetite $\left(\mathrm{Fe}_{3} \mathrm{O}_{4}\right)$, DI-water, and the water base magnetic fluid and their corresponding magnitude used in this numerical simulation are given as a tabular form" (Saha S, Chakrabarti S. 2020).

Table 1. Physical property of the magnetic nanoparticle, DI-water, and magnetic fluid.

\begin{tabular}{|c|c|c|}
\hline Magnetic particle and fluid & Density $(\boldsymbol{\rho})$ & $\operatorname{Viscosity}(\boldsymbol{\mu})$ \\
\hline Magnetite & 4950 & \\
\hline DI-Water & 997 & 0.00065 \\
\hline Magnetic fluid & 1076 & 0.00069 \\
\hline
\end{tabular}

\subsection{Numerical Procedure}

In this examination, the governing $2 \mathrm{D}$ continuity and momentum equations (i.e., equations 1 to 3 ) have been tackled with the guide of finite volume techniques. To discretize the convective and diffusive terms of the equations, the power-law scheme is utilized. The discretized equations are iteratively being solved by the SIMPLE algorithm, utilizing line-by-line ADI (alternating directional implicit) technique. The distribution of grid nodes has been viewed as uniform along both $\mathrm{x}$ - and $\mathrm{y}$-directions. At whatever instant of time, the normalized residuals for both mass and momentum equations over whole computation space fall under $10^{-6}$; at that instant of time, the convergence of the iterative plan is viewed as accomplished.

In this work, "the magnitude of length and height of the channel are considered as $1.0 \mathrm{~m}$ and $0.05 \mathrm{~m}$, respectively, for an end-to-end simulation. For the entire calculation, the values of density $(\rho)$ and viscosity $(\mu)$ are taken from table 1. Apart from that, the electrical conductivity $(\sigma)$ is considered to remain unchanged and is equal to $1.0 \times 10^{6}$ /ohm- m" (Saha S, Chakrabarti S. 2020).

Now, after considering the pressure gradient term separately, the x-momentum discretization equation for the velocity of "u" becomes $a_{e} u_{e}=\sum a_{n b} u_{n b}+b+\left(p_{p}-p_{E}\right) A_{e}$.

Similarly, the other y-momentum discretization equation for velocity " $v$ " can be written as 
$a_{n} v_{n}=\sum a_{n b} v_{n b}+b+\left(p_{p}-p_{N}\right) A_{n}$

Here, the term $\left(p_{p}-p_{E}\right) A_{e}$ and other similar terms illustrate the pressure force, which is acting on the respective control volume of the velocity. ' $\mathrm{A}$ ' is an area where differential pressure is applied. The subscript ' $n b$ ' represents the neighboring grid points.

At this point, it is known that if the pressure field is given or is somehow estimated, the momentum equation can be solved. It can also be said that unless the correct pressure field is used, the continuity equation is not satisfied with the resulting velocity field. Based on the guessed pressure field, the velocity field is denoted by $p^{*}$, represented as $u^{*}$ and $v^{*}$. Therefore, the imperfect velocity field is obtained through the discretization of the following equations:

$a_{e} u_{e}^{*}=\sum a_{n b} u_{n b}^{*}+b+\left(p_{p}^{*}-p_{E}^{*}\right) A_{e}$

$a_{n} v_{n}^{*}=\sum a_{n b} v_{n b}^{*}+b+\left(p_{p}^{*}-p_{N}^{*}\right) A_{n}$

Now, the attempt should be taken to enhance the guessed pressure $p^{*}$ in such a way that the resulting imperfect velocity field gradually moves closer to satisfying the continuity equation. For that, let us propose the computation of correct pressure as $p=p^{*}+p^{\prime}$,

where $p /$ denotes the pressure correction. This change in the pressure certainly affects the velocity components. The corresponding velocity corrections $u^{\prime}$ and $v^{\prime}$ can be similarly represented as $u=u^{*}+u^{\prime}$ and $v=v^{*}+v^{\prime}$.

If the equation $a_{e} u_{e}^{*}=\sum a_{n b} u_{n b}^{*}+b+\left(p_{p}^{*}-p_{E}^{*}\right) A_{e}$

is subtracted from the equation $a_{e} u_{e}=\sum a_{n b} u_{n b}+b+\left(p_{p}-p_{E}\right) A_{e}$,

then we have $a_{e} u_{e}^{\prime}=\sum a_{n b} u_{n b}^{\prime}+\left(p_{p}^{\prime}-p_{E}^{\prime}\right) A_{e}$.

Drop the term $\sum a_{n b} u_{n b}^{\prime}$; then, the above equation will be as

$a_{e} u_{e}^{\prime}=\left(p_{p}^{\prime}-p_{E}^{\prime}\right) A_{e}$.

Therefore, the above equation can be written as $u_{e}^{\prime}=d_{e}\left(p_{p}^{\prime}-p_{E}^{\prime}\right)$,

where $d_{e}=\frac{A_{e}}{a_{e}}$.

So, the corrected formula of velocity is obtained as $u_{e}=u_{e}^{*}+d_{e}\left(p_{p}^{\prime}-p_{E}^{\prime}\right)$.

These equatiosn demonstrate an imperfect velocity $u_{e}^{*}$ that is required to be adjusted according to the pressure correction to get $u_{e}$. Other components of velocity can also be similarly written as $v_{n}=v_{n}^{*}+$ $d_{n}\left(p_{p}^{\prime}-p_{E}^{\prime}\right)$ 
To get the pressure correction equation, velocity components are transformed into the discretized form of the continuity equation. Subsequently, the discretized equation for pressure correction can be expressed as

$a_{P} p_{P}^{\prime}=a_{E} p_{E}^{\prime}+a_{W} p_{W}^{\prime}+a_{N} p_{N}^{\prime}+a_{S} p_{S}^{\prime}+b_{P}$.

where $a_{E}, a_{W}, a_{N}$ and $a_{s}$ are the coefficients, and $b_{P}$ is the source term for pressure node and can be expressed by using the power low as

$a_{E}=\rho_{e} d_{e} \Delta y$

$a_{W}=\rho_{w} d_{w} \Delta y, \quad a_{N}=\rho_{n} d_{n} \Delta x, a_{S}=\rho_{s} d_{s} \Delta x$,

$a_{P}=a_{E}+a_{W}+a_{N}+a_{S}$,

$b_{P}=\left[\left(\rho u^{*}\right)_{w}-\left(\rho u^{*}\right)_{e}\right] \Delta y+\left[\left(\rho v^{*}\right)_{s}-\left(\rho v^{*}\right)_{n}\right] \Delta x$.

Now, the discretization equation for velocity $\mathrm{u}$ can be expressed as

$a_{P} u_{P}=\sum a_{n b} u_{n b}=a_{E} u_{E}+a_{W} u_{W}+a_{N} u_{N}+a_{S} u_{S}+b_{u}$.

where $a_{E}, a_{W}, a_{N}, a_{S}$ and $a_{P}$ are the coefficients, and $b_{u}$ is the source term and can be expressed by using the power low as

$a_{E}=D_{e} \max \left[0,\left(1-0.1\left|P_{e}\right|\right)^{5}\right]+\max \left(-F_{e}, 0\right)$,

$a_{W}=D_{w} \max \left[0,\left(1-0.1\left|P_{w}\right|\right)^{5}\right]+\max \left(-F_{w}, 0\right)$,

$a_{N}=D_{n} \max \left[0,\left(1-0.1\left|P_{n}\right|\right)^{5}\right]+\max \left(-F_{n}, 0\right)$,

$a_{S}=D_{s} \max \left[0,\left(1-0.1\left|P_{S}\right|\right)^{5}\right]+\max \left(-F_{S}, 0\right)$,

$a_{P}=a_{E}+a_{W}+a_{N}+a_{S}$,

$b_{u}=\left(P_{w}-P_{e}\right) \Delta y+M_{n F} \Delta x \Delta y$.

where $D_{e}, D_{w}, D_{n}$ and $D_{s}$ are the diffusion of flow per unit area at east, west, north, and south faces, respectively, $F_{e}, F_{w}, F_{n}$ and $F_{s}$ are the mass flux per unit area of flow area at east, west, north, and south faces, respectively, and $P_{e}, P_{w}, P_{n}$ and $P_{s}$ are the peclet number area at east, west, north, and south faces, respectively, and can be expressed as

$D_{e}=\mu \frac{\Delta y}{\Delta x_{e}} ; F_{e}=(\rho u)_{e} \Delta y ; \quad P_{e}=\frac{F_{e}}{D_{e}}$,

$D_{w}=\mu \frac{\Delta y}{\Delta x_{w}} ; F_{w}=(\rho u)_{w} \Delta y ; P_{w}=\frac{F_{w}}{D_{w}}$,

$D_{n}=\mu \frac{\Delta x}{\Delta y_{n}} ; F_{n}=(\rho u)_{n} \Delta x ; \quad P_{n}=\frac{F_{n}}{D_{n}}$,

$D_{s}=\mu \frac{\Delta x}{\Delta y_{s}} ; F_{s}=(\rho u)_{s} \Delta x ; P_{s}=\frac{F_{s}}{D_{s}}$.

Similarly, the discretization equation for velocity $\mathrm{v}$ can be expressed as 
$a_{P} v_{P}=\sum a_{n b} v_{n b}=a_{E} v_{E}+a_{W} v_{W}+a_{N} v_{N}+a_{S} v_{S}+b_{v}$

where $a_{E}, a_{W}, a_{N}, a_{S}$ and $a_{P}$ are the coefficients, and $b_{v}$ is the source term and can be expressed by using the power low as

$a_{E}=D_{e} \max \left[0,\left(1-0.1\left|P_{e}\right|\right)^{5}\right]+\max \left(-F_{e}, 0\right)$,

$a_{W}=D_{w} \max \left[0,\left(1-0.1\left|P_{w}\right|\right)^{5}\right]+\max \left(-F_{w}, 0\right)$,

$a_{N}=D_{n} \max \left[0,\left(1-0.1\left|P_{n}\right|\right)^{5}\right]+\max \left(-F_{n}, 0\right)$,

$a_{S}=D_{S} \max \left[0,\left(1-0.1\left|P_{S}\right|\right)^{5}\right]+\max \left(-F_{S}, 0\right)$,

$a_{P}=a_{E}+a_{W}+a_{N}+a_{S}$,

$b_{v}=\left(P_{s}-P_{n}\right) \Delta x$.

where $D_{e}, D_{w}, D_{n}$ and $D_{s}$ are the diffusion of flow per unit area at east, west, north, and south faces, respectively, $F_{e}, F_{w}, F_{n}$ and $F_{s}$ are the mass flux per unit area of flow area at east, west, north, and south faces, respectively, and $P_{e}, P_{w}, P_{n}$ and $P_{s}$ are the peclet number area at east, west, north, and south faces, respectively, and can be expressed as

$D_{e}=\mu \frac{\Delta y}{\Delta x_{e}} ; F_{e}=(\rho u)_{e} \Delta y ; \quad P_{e}=\frac{F_{e}}{D_{e}}$,

$D_{w}=\mu \frac{\Delta y}{\Delta x_{w}} ; F_{w}=(\rho u)_{w} \Delta y ; P_{w}=\frac{F_{w}}{D_{w}}$,

$D_{n}=\mu \frac{\Delta x}{\Delta y_{n}} ; F_{n}=(\rho u)_{n} \Delta x ; \quad P_{n}=\frac{F_{n}}{D_{n}}$,

$D_{s}=\mu \frac{\Delta x}{\Delta y_{s}} ; F_{s}=(\rho u)_{s} \Delta x ; P_{s}=\frac{F_{s}}{D_{s}}$.

In the case of the SIMPLE algorithm, the following sequential steps of the operation to execute the computational simulations are considered:

1. Pressure field $p^{*}$ (guess)

2. Solve the discretized momentum equation to attain $u^{*}, v^{*}$

3. To obtain the corrected equation of pressure, it is substituted in the velocity correction formula and expressed in the form of pressure corrections, which is finally done at the main grid points in the discretized continuity equation.

4. The pressure field has been corrected with the help of the expression, $p=p^{*}+p^{\prime}$.

5. The velocity field has been rectified by using the following expressions: $u_{e}=u_{e}^{*}+d_{e}\left(p_{p}^{\prime}-p_{E}^{\prime}\right) v_{n}=v_{n}^{*}+d_{n}\left(p_{p}^{\prime}-p_{N}^{\prime}\right)$.

6. Consider the corrected pressure $p$, which is gained from the above-mentioned step 4, as a new guessed pressure $p^{*}$

7. Reiterate the entire process till the convergence of the solutions is attained. 


\subsection{Grid Independence Test}

In this work, several test cases are run by using different grid nodes to quantify grid independence study in terms of the magnitude of stream function (i.e., $\Psi_{\max }$ ) and its location in the channel. Finally, the numerical mesh comprised of $1001 \times 51$ grid nodes in the $\mathrm{x}$ - and $\mathrm{y}$-directions for the whole computational domain has been considered, as it combines accuracy with the considerable computational economy.

\subsection{Code Validation}

In this investigation, code validation has been performed by comparing the present work with the work presented by Akram et al. (2013) in terms of the velocity profile. Both velocity profiles are shown in figure 2 . From the figure, it has been seen that there is a good agreement between the quantitative results of the present numerical work and the numerical work of Akram et al. (2013).

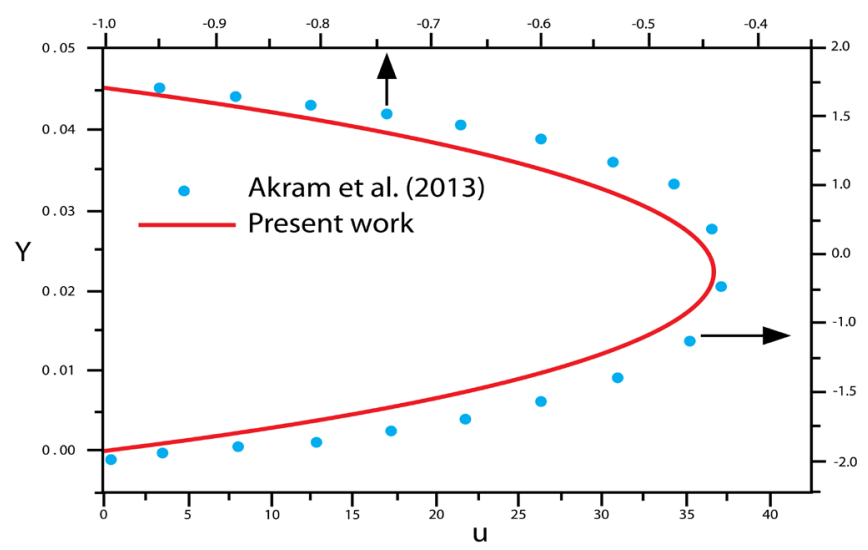

Figure 2. The velocity profile ofpresent work and Akram et al. (2013).

\section{NUMERICAL RESULTS AND ITS DISCUSSION}

\subsection{Streamline contour and vorticity}

In the case of the dynamics of magnetic fluid flow, the flow field near the magnetic zone has become a great interest for the researchers to observe the influence of the magnetic field on the magnetic fluid flow. It has been observed that the most accepted approach to illustrate the various laminar or turbulent flow along with different conditions has been done by displaying streamline contour and vorticity contour. In this work, a sincere effort has been given to supplement the flow patterns, which is achieved at the time of investigation by presenting the streamline contour and vorticity contour at different axial locations of the channel. The flow with recirculation becomes an important criterion when viewed as a heat exchanger, mixing chamber, diffuser, and other industrial equipment. This flow field contains a separated boundary layer and a recirculation region. For a given surface area of a heat exchanger, the generation of the recirculating zone affects mainly the enhancement of heat transfer, as the recirculating bubble increases the retention time of the fluid in the channel.

The impact of the magnetic number emerging from MHD extending from 302 to 777 for a fixed estimation of Reynolds number of 100 on streamline and vorticity contours of the flow has been delineated in Figure 3 successively. From the figure of the streamline contours, it has been noticed that the number of the same sort of recycling zones is 
made in the channel, yet they are diverse concerning their size, area, and their counts. The plausible explanation might be the applied magnetic field on the magnetic molecule. It causes velocity change as well as the generation of bubbles. It has been observed from the contour of vorticity that, for all the thought about cases, vorticity fixations are framed at a similar area of the recycling bubbles. It has likewise been noted that the size and the quantity of the vorticity fixation rely upon the size and the quantity of the recycling bubble.
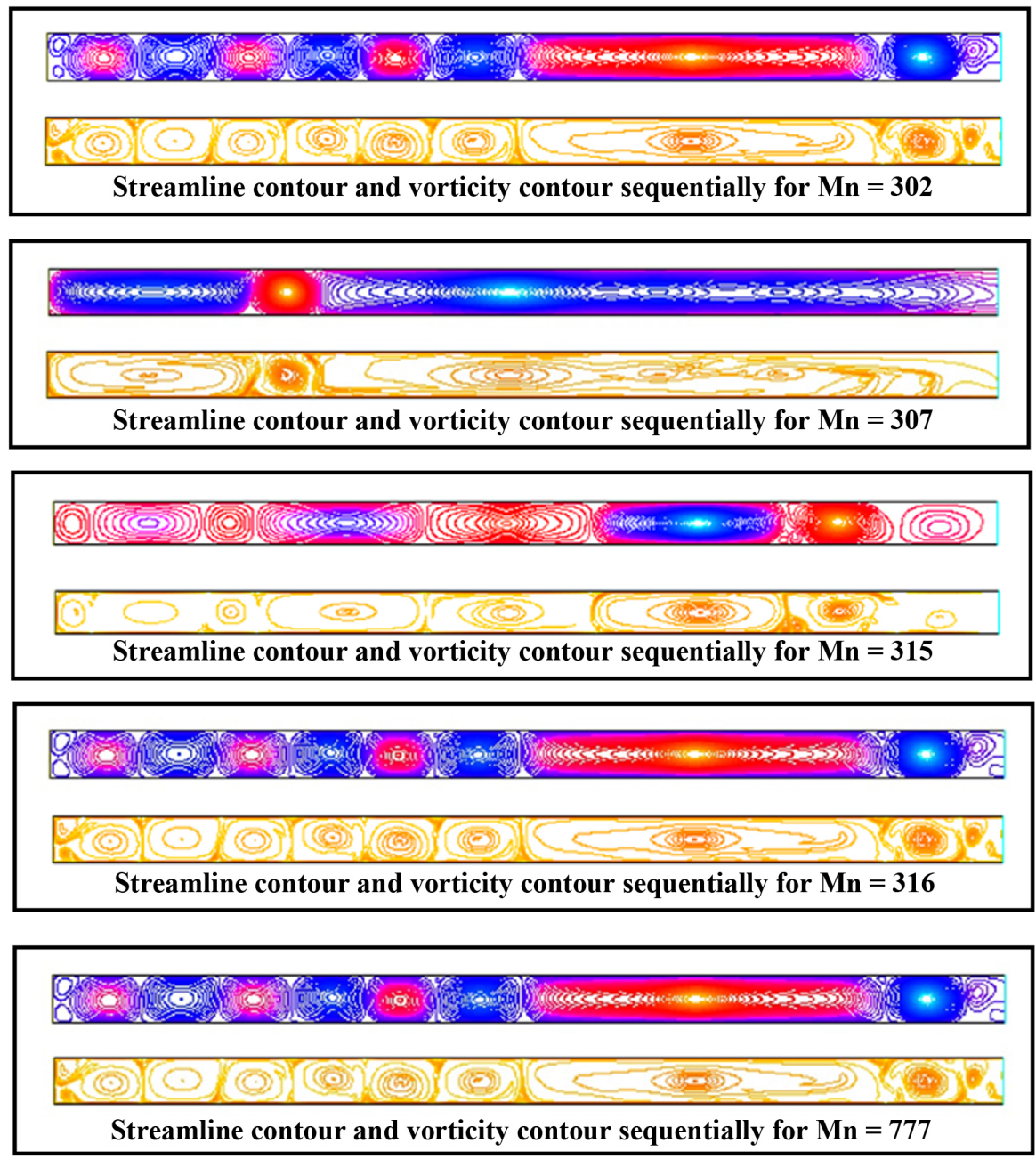

Figure 3. Effect of Magnetic number $(\mathrm{MnF})$ on the streamline contour and vorticity contour for $\mathrm{Re}=100$.

\subsection{Variation of Wall Shear Stress}

In this subsection, the impact of magnetic number $\left(\mathrm{M}_{\mathrm{nM}}\right)$ emerging from $\mathrm{MHD}$ on upper and lower wall shear stress has been explored and has been introduced in detail. Figures 4(a) and 4(b) represent the variety of the top wall and the base wall shear separately for various magnetic numbers of 302, 307, 315, 316, and 777 and for a typical Reynolds number of 100. In this subsection, the most elevated extents of the wall shear have been processed and introduced for various magnetic numbers. From the plots, it has been revealed that almost a comparable kind of bends for top wall stress has been noted for all the magnetic numbers $\left(\mathrm{M}_{\mathrm{nM}}\right)$. Notwithstanding this, the bends are disparate 
regarding their values and their areas. The likely explanation might be because of the electromagnetic power, applied on the magnetic molecule while moving in the channel. Accordingly, the liquid stream is disturbed, and the velocity of the stream is changed. Hence, it might be determined that the change in magnetic numbers emerging from MHD might be a solid explanation for the variety of upper wall shear. Figure 4(b) presents the variety of the base wall shear for the equivalent magnetic numbers. A practically comparable sort of undulation of the base wall shear has been noted for all the magnetic numbers $\left(\mathrm{M}_{\mathrm{nM}}\right)$ of $307,315,316$, and 777 , be that as it may, and the outcomes are distinctive regarding their most noteworthy extent and their relating area. The likely explanation for the variety has been clarified before.

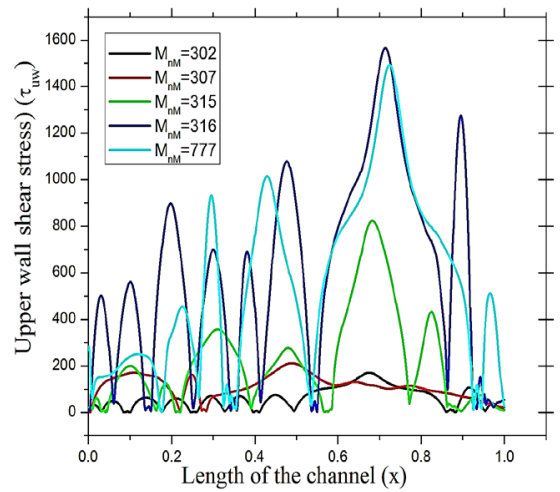

(a)

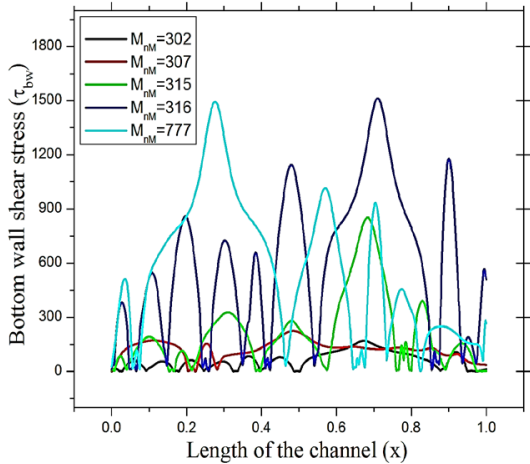

(b)

Figure 4. Effect of magnetic number $\left(\mathrm{M}_{\mathrm{nF}}\right)$ on upper and bottom wall shear stress for $\mathrm{R}_{\mathrm{e}}=100$.

For various magnetic numbers, the most noteworthy shear values of top and base walls have been introduced in table 2, considering a similar condition utilized in Figures 4(a) and 4(b).

Table 2. The highest magnitude of the upper wall and the bottom wall shear stress $\left(\boldsymbol{\tau}_{\boldsymbol{u}}\right.$ and $\left.\boldsymbol{\tau}_{\boldsymbol{b}}\right)$ for different magnetic numbers $\left(\mathrm{M}_{\mathrm{nM}}\right)$.

\begin{tabular}{|c|c|c|c|c|}
\hline $\begin{array}{c}\text { Magnetic } \\
\text { number }\end{array}$ & \multicolumn{2}{|c|}{$\begin{array}{c}\text { Highest value of upper wall shear stress } \\
\text { with its position }\end{array}$} & \multicolumn{2}{c|}{$\begin{array}{c}\text { Highest value of bottom wall shear stress } \\
\text { with its position }\end{array}$} \\
\hline $\mathrm{M}_{\mathrm{nM}}$ & $\tau_{u}$ & $\mathrm{~L}$ & $\tau_{b}$ & $\mathrm{~L}$ \\
\hline 302 & 170.780 & 0.671 & 170.561 & 0.674 \\
\hline 307 & 211.272 & 0.489 & 225.187 & 0.484 \\
\hline 315 & 822.745 & 0.683 & 851.248 & 0.682 \\
\hline 316 & 1565.53 & 0.741 & 1512.29 & 0.711 \\
\hline 777 & 1892.66 & 0.724 & 1892.66 & 0.278 \\
\hline
\end{tabular}

From table 2, it is apparent that, for a magnetic number of 316 (i.e., $\mathrm{M}_{\mathrm{nM}}=316$ ), the extent of both the shear highly contrasted that for the other magnetic numbers. In this manner, it might be found out that there might be an ideal estimation of magnetic number $\left(\mathrm{M}_{\mathrm{nM}}\right)$ emerging from $\mathrm{MHD}$, for which the groundbreaking outcomes might be begotten according to the need of the modern and the clinical applications. 


\subsection{Variation of Wall Static Pressure}

In planning the modern and clinical equipment, the wall static pressure might be chosen as a significant parameter, when thinking about the metallurgical perspective.
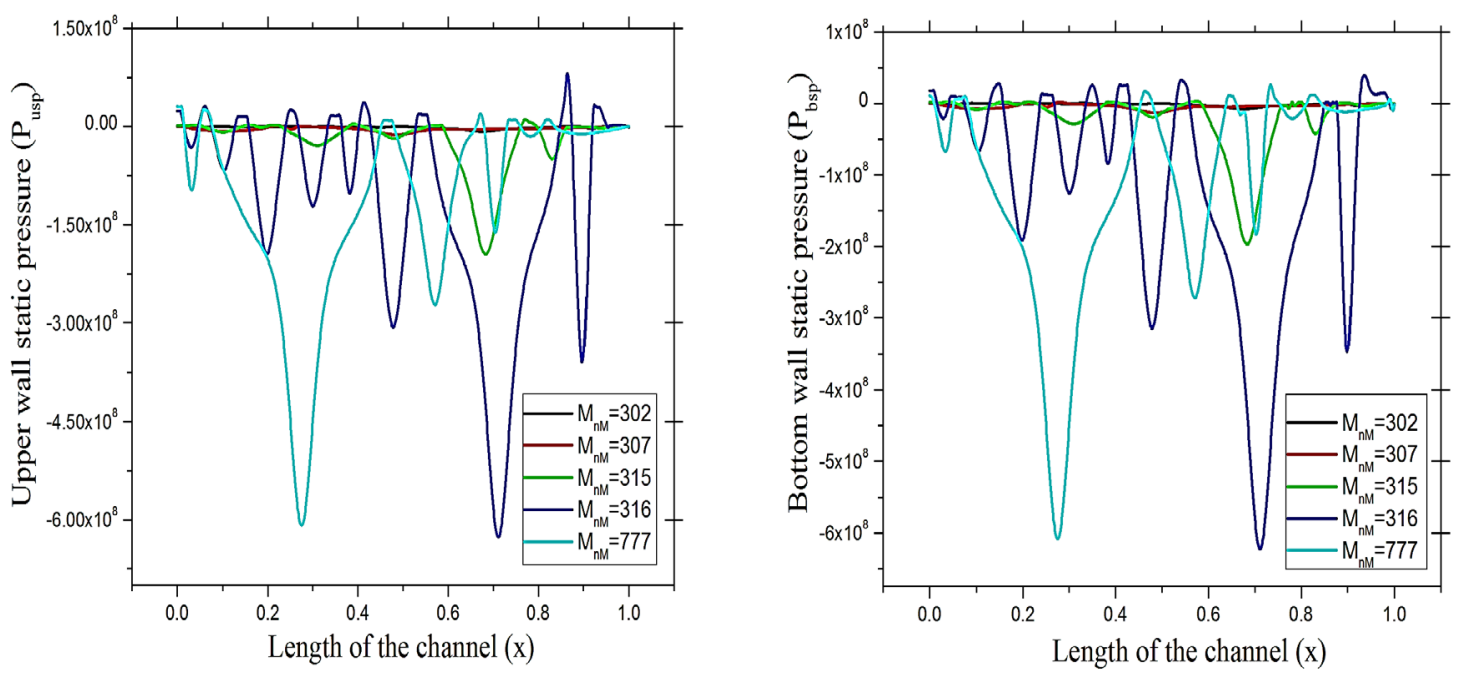

Figure 5. Effect of magnetic number $\left(\mathbf{M}_{\mathbf{n} \mathbf{M}}\right)$ on the upper and bottom wall static pressure for $\mathrm{Re}=100$.

Figures 5(a) and 5(b) present the variety of top wall pressure and base wall pressure individually for various magnetic numbers $\left(\mathrm{M}_{\mathrm{nM}}\right)$ of 302, 307, 315, 316, and 777 and a predetermined Reynolds number $(\mathrm{Re})$ of 100 . From plots of the upper wall pressure in Figure 5(a), it has been seen that the general attribute of the considerable number of bends is the same, yet they are not indistinguishable. These are particular as for their most noteworthy highest and least values and their areas. For all considered $\mathrm{M}_{\mathrm{nM}}$, the extent of pressure on the top wall undulates over the whole test segment. The explanation might be credited because of the imposed magnetic field. This outer magnetic field opposes the motion of magnetic liquid particles while moving, because of which the kinetic head of the liquid molecule is changed over into the pressure head. The most elevated and least values of pressure of the top wall have been introduced in Table 3 taking into consideration a similar condition utilized in Figure 5(a). In Table 3, the values of the above-mentioned pressure increment with an increment of $\mathrm{M}_{\mathrm{nM}}$ are noticed. A higher extent of wall static pressure might be utilized to improve the proficiency of the power plant. 
Table 3. The highest and the lowest magnitudes of the upper wall pressure $\left(\boldsymbol{p}_{\text {stu }}\right)$ for the different magnetic numbers (MnM).

\begin{tabular}{|c|c|c|c|c|}
\hline $\begin{array}{c}\text { Magnetic } \\
\text { number }\end{array}$ & \multicolumn{2}{|c|}{$\begin{array}{c}\text { Highest magnitude and } \\
\text { its position }\end{array}$} & \multicolumn{2}{c|}{$\begin{array}{c}\text { Lowest magnitude and } \\
\text { its position }\end{array}$} \\
\hline $\mathrm{M}_{\mathrm{nM}}$ & $p_{\text {stu }}$ & $L_{h}$ & $p_{\text {stu }}$ & $L_{l}$ \\
\hline 302 & $4.72 \times 10^{5}$ & 0.494 & $-7.94 \times 10^{6}$ & 0.676 \\
\hline 307 & $1.62 \times 10^{6}$ & 0.22 & $-1.28 \times 10^{7}$ & 0.486 \\
\hline 315 & $1.08 \times 10^{7}$ & 0.771 & $-1.95 \times 10^{8}$ & 0.683 \\
\hline 316 & $8.08 \times 10^{7}$ & 0.856 & $-6.26 \times 10^{8}$ & 0.712 \\
\hline 777 & $10.11 \times 10^{7}$ & 0.000 & $-7.09 \times 10^{8}$ & 0.275 \\
\hline
\end{tabular}

Table 4. The highest and lowest magnitudes of bottom wall pressure $\left(p_{\text {stu }}\right)$ for different magnetic number $\left(\mathrm{M}_{\mathrm{nM}}\right)$.

\begin{tabular}{|c|c|c|c|c|}
\hline $\begin{array}{c}\text { Magnetic } \\
\text { number }\end{array}$ & \multicolumn{2}{|c|}{$\begin{array}{c}\text { Highest magnitude and } \\
\text { its position }\end{array}$} & \multicolumn{2}{c|}{$\begin{array}{c}\text { Lowest magnitude and } \\
\text { its position }\end{array}$} \\
\hline $\mathrm{M}_{\mathrm{nM}}$ & $p_{\text {stu }}$ & $L_{h}$ & $p_{\text {stu }}$ & $L_{l}$ \\
\hline 302 & $4.20 \times 10^{5}$ & 0.396 & $-7.93 \times 10^{6}$ & 0.675 \\
\hline 307 & $1.86 \times 10^{6}$ & 0.28 & $-1.29 \times 10^{7}$ & 0.487 \\
\hline 315 & $3.12 \times 10^{7}$ & 0.577 & $-1.97 \times 10^{8}$ & 0.683 \\
\hline 316 & $3.91 \times 10^{7}$ & 0.936 & $-6 . .22 \times 10^{8}$ & 0.711 \\
\hline 777 & $2.61 \times 10^{7}$ & 0.734 & $-6.08 \times 10^{8}$ & 0.275 \\
\hline
\end{tabular}

Figure 5(b) delineates the variety of the base wall pressure as for the various magnetic numbers. For every single magnetic number (i.e., $\mathrm{M}_{\mathrm{nM}}=302, \mathrm{M}_{\mathrm{nM}}=307, \mathrm{M}_{\mathrm{nM}}=315, \mathrm{M}_{\mathrm{nM}}=316$ and $\mathrm{M}_{\mathrm{nM}}=777$ ), it has been additionally noticed that the greatness of the base wall pressure vacillates all through the length of the text segment. Its likely explanation has been clarified before. The general characteristic of bends of the base wall pressure is the same for all magnetic numbers; in any case, they are diverse concerning their most elevated and least extent and as for their location. The most noteworthy highest and least values of pressure of the base wall have been expressed in Table 4 considering similar settings utilized in Figure 5(b). In Table 4, with increment in the magnetic number, there is the most noteworthy extent of the base wall pressure increments.

\section{CONCLUSION}

In this study, a conscientious exertion has been provided to consider an enhancement of heat transfer in a heat exchanger under the effect of the magnetic field. The impact of magnetic number emerging from MHD on the development of flow characteristics is also studied. This prompts the accompanying significant end: 
1. Augmentation of heat transfer may be done in a heat exchanger with the help of an applied magnetic field for a given surface area, and that is happened due to the formation of a recirculating zone. Consequently, the size and cost of the production of the heat exchanger may reduce.

2. The flow characteristics are impressively influenced because of the nearness of the magnetic field.

\section{REFERENCES}

Abd-Alla AM, Yahya GA, Mahmoud SR, Alosaimi HS. 2012. Effect of the rotation, magnetic field and initial stress on peristaltic motion of micropolar fluid. Meccanica. 47(6): 1455-1465.

Akram S, Nadeem S, Hanif M. 2013. Numerical and analytical treatment on peristaltic flow of Williamson fluid in the occurrence of induced magnetic field. Journal of Magnetism and Magnetic Materials. 346: 142-151.

Akram S, Nadeem S. 2014. Consequence of nanofluid on peristaltic transport of a hyperbolic tangent fluid model in the occurrence of apt (tending) magnetic field. Journal of Magnetism and Magnetic Materials. 358: 183189.

Aminfar H, Mohammadpourfard M, Ghaderi F. 2012. Two-phase simulation of non-uniform magnetic field effects on biofluid (blood) with magnetic nanoparticles through a collapsible tube. Journal of Magnetism and Magnetic Materials. 332: 172-179.

Azizian R, Doroodchi E, McKrell T, Buongiorno J, Hu LW, Moghtaderi B. 2014. Effect of magnetic field on laminar convective heat transfer of magnetite nanofluids. International Journal of Heat and Mass Transfer. 68: 94-109.

Asif A, Mohammed S A D, Abdul R R K. 2019. Experimental investigation of thermal performance of engine oil and water in helical coil heat exchanger. Journal of Engg. Research. 7(2): 333-351.

Abo-Dahab1 S M, Abdelhafez M A, Mebarek-Oudina F, Bilal S M. 2021. MHD Casson nanofluid flow over nonlinearly heated porous medium in presence of extending surface effect with suction/injection. Indian $\mathrm{J}$ Phys. https://doi.org/10.1007/s12648-020-01923-z

Bitla P, Iyengar TVV. 2014. Pulsating flow of an incompressible micropolar fluid between permeable beds with an inclined uniform magnetic field. European Journal of Mechanics - B/Fluids. 48: 1-16.002

Dritselis CD, Knaepen B. 2014. Mixed convection of a low Prandtl fluid with spatially periodic lower wall heating in the presence of a wall-normal magnetic field. International Journal of Heat Mass Transfer. 74: 3547.

Gedik E, Kurt H, Recebli Z, Balan C. 2012. Two-dimensional CFD simulation of magnetorheological fluid between two fixed parallel plates applied external magnetic field. Computer Fluids. 63: 128-134.

Galindo V, Niemietz K, Pätzold O, Gerbeth G. 2012. Numerical and experimental modelling of VGF-type buoyant flow under the influence of traveling and rotating magnetic fields. Journal of Crystal Growth. 360: 30-34.

Hayat T, Afsar A, Khan M, Asghar S.2007. Peristaltic transport of a third order fluid under the effect of a magnetic field. Computers \& Mathematics with Applications. 53(7): 1074-1087.

Hayat T, Noreen S, Alsaedi A. 2012. Slip and induced magnetic field effects on peristaltic transport of JohnsonSegalman fluid. Applied Mathematics and Mechanics. 33(8): 1035-48.

Khashan SA, Elnajjar E, Haik Y. 2011. Numerical simulation of the continuous biomagnetic separation in a two-dimensional channel. International Journal of Multiphase Flow. 37(8): 947-955. 
Kolsi L, Algarni S, Mohammed H A, Hassen W, Lajnef E, Aich W, Almeshaal M A. 2020. 3D MagnetoBuoyancy-Thermocapillary Convection of CNT-Water Nanofluid in the Presence of a Magnetic Field. Processes.258(8): 1-16. DOI: 10.3390/pr8030258

Malekzadeh A, Heydarinasab A, Jahangiri M. 2011. Magnetic field effect on laminar heat transfer in a pipe for thermal entry region. Journal of Mechanical Science and Technology. 25(4): 877-884.

Muthtamilselvan M, Doh DH. 2014. Magnetic field effect on mixed convection in a lid-driven square cavity filled with nanofluids. Journal of Mechanical Science and Technology. 28(1): 137-143.

Maatki C, Hassen W, Kolsi L, AlShammari N, Borjini M N, Aissia H B. 2016. 3-D Numerical Study of Hydromagnetic Double Diffusive Natural Convection and Entropy Generation in Cubic Cavity. Journal of Applied Fluid Mechanics. DOI: 10.18869/acadpub.jafm.68.235.24820

Maatki C, Kolsi L, Ghachem K, Alghamdi A S, Borjini M N, Aissia H B. 2017. Numerical analysis of electromagnetic parameters of thermal dominated double diffusive magneto- convection. Journal of Engg. Research. 5(3): 198-215.

Mebarek-Oudina F. 2017. Numerical modeling of the hydrodynamic stability in vertical annulus with heat source of different lengths. Engineering Science and Technology, an International Journal. 20: 1324-1333.

Mebarek-Oudina F, Redouane F, Rajashekhar C. 2020. Convection Heat Transfer of MgO-Ag Water Magneto-Hybrid Nanoliquid Flow into a Special Porous Enclosure. Algerian Journal of Renewable Energy and Sustainable Development. 2(1): 84-95.

Mebarek-Oudina F, Bessaih R, Mahanthesh B, Chamkha A J, Raza Z. 2020. Magneto-thermal-convection stability in an inclined cylindrical annulus filled with a molten metal. International Journal of Numerical Methods for Heat \& Fluid Flow. DOI: 10.1108/HFF-05-2020-0321

Marzougui S, Bouabid M, Mebarek-Oudina F, Abu-Hamdeh N, Magherbi M, RameshK. 2020. A computational analysis of heat transport irreversibility phenomenon in a magnetized porous channel. International Journal of Numerical Methods for Heat \& Fluid Flow. DOI: 10.1108/HFF-07-2020-0418

Saha S, Chakrabarti S. 2016. MHD Modelling and Numerical Simulation on ferromagnetic Fluid Flow in a Channel. International Journal of Fluid Mechanics Research. 43(1): 79-92.

Saha S, Chakrabarti S. 2020. Numerical Simulation on the Magnetic Fluid Flow through a Channel. Indian Journal of Engineering. 17(47): 117-126.

Srivastava BG, Deo S. 2013. Effect of magnetic field on the viscous fluid flow in a channel filled with porous medium of variable permeability. Applied Mathematics and Computation. 219(17): 8959-8964.

Swain1 K, Mebarek-Oudina F, Abo-Dahab S M. 2020. Influence of MWCNT/ $/ \mathrm{Fe}_{3} \mathrm{O}_{4}$ hybrid nanoparticles on an exponentially porous shrinking sheet with chemical reaction and slip boundary conditions. Journal of Thermal Analysis and Calorimetry. https://doi.org/10.10

Takeuchi J, Satake SI, Morley NB, Kunugi T, Yokomine T, Abdou MA. 2008. Experimental study of MHD effects on turbulent flow of FlibeSimulent fluid in circular pipe. Fusion Engineering and Design. 83(7): 10821086.

Turk O, Bozkaya C, Tezer-Sezgin M. 2014. A FEM approach to biomagnetic fluid flow in multiple stenosed channels. Computers \& Fluids. 97: 40-51.

ThankGod Enatimi Boye, Olusegun David Samile. 2020. Computer-based method of design and modeling of transient flow in crude oil piprline system. Journal of Engg. Research. 8(3): 219-239.

Zaima A, Aissab A, Mebarek-Oudinac F, MahanthesheB,Lorenzinif G, Sahnounb M, GanaouigM. El. 2020. Galerkin finite element analysis of magneto hydrodynamic natural convection of $\mathrm{Cu}$-water nanoliquid in a baffled U-shaped enclosure. Propulsion and Power Research. 9(4): 383-393. 